\title{
Breastfeeding Practice in Zhejiang Province, PR China, in the Context of Melamine-contaminated Formula Milk
}

\author{
Liqian Qiu',2, Colin W. Binns', Yun Zhao', \\ Andy H. Lee', and Xing $\mathrm{Xie}^{2}$ \\ 'School of Public Health, Curtin Health Innovation Research Institute, Curtin University of Technology, Perth,WA, Australia and \\ 2Women's Hospital, School of Medicine, Zhejiang University, Hangzhou, China
}

\begin{abstract}
A prospective cohort study of 1,520 mothers from Zhejiang province of China was undertaken to determine the duration of breastfeeding and associated factors during the first six months postpartum. Most (95.3\%) mothers had introduced complementary foods by six months, making them at risk from contaminated infant formula. The mean duration of 'any breastfeeding' was greater than 180 days but only 48 days for 'exclusive breastfeeding'. Factors relating to cessation of any breastfeeding were maternal age, timing of the breastfeeding decision, admission of the infant to a special-care nursery, return of the mother to work, the early introduction of water and/or other complementary foods, and their location of residence. The introduction of infant formula before three months was positively associated with the late decision to breastfeed, births in city, and infants being given a prelacteal feed. To combat the melamine disaster, strategies to improve the duration of breastfeeding must be developed taking these factors into account.
\end{abstract}

Key words: Breastfeeding; Cohort studies; Disasters; Exclusive breastfeeding; Melamine; Melamine disasters; Prospective studies; China

\section{INTRODUCTION}

A recent market report concluded that the production of infant formula in the world was 907,000 tonnes during 2008, and the market is still growing rapidly. Sales were valued at US\$ 9 billion, and 53\% of the market was in Asia (1). China is the largest market for infant formula in the world, a market shared by the major companies for multi-national formula and about 150 local producers.

The recent contamination of infant formula with melamine in China has caused a public-health crisis, with reports of at least 50,000 infants admitted to hospitals with renal stones (2). Melamine has high nitrogen content and is added to milk to conceal the low protein content. Little information is available on

Correspondence and reprint requests should be addressed to:

Professor Andy H. Lee

School of Public Health

Curtin University of Technology

GPO Box U, Perth, WA 6845

Australia

Email: Andy.Lee@curtin.edu.au

Fax: +61-8-92662958 the toxicity of melamine in humans but it is known to cause renal calculi, renal failure, and haematuria $(2,3)$. Immediately following notification of the contamination, mothers of children aged less than three years were asked to contact their local child-health clinic. In total, 1.5 million infants were screened in Zhejiang province for the use of formula brands that had been contaminated while 3,000 infants were admitted to hospitals for further assessment.

Internationally, exclusive breastfeeding is recommended until six months of age and then continued breastfeeding for 12 months and beyond (4-7). Breastfeeding has been emphasized in public-health programmes by the Chinese Ministry of Health, particularly over the past two decades. It was the centre piece of the "National Program of Action for Child Development in China in the 1990's" issued in 1994 (8). In traditional Chinese society, breastfeeding was always the focus of child health. However, despite recent increases, breastfeeding rates have still not reached the national targets.

Identifying the subgroup of mothers with earlier introduction of formula and shorter duration of breastfeeding is an important public-health strate- 
gy because they are susceptible to contaminated infant formula. Results of studies in China and Viet Nam suggest that successful breastfeeding depends on many factors relating to the mother, the infant, and the surrounding environment. The duration of breastfeeding has been shown to be positively associated with maternal age, maternal education, the hospital environment, timing of the decision to breastfeed, early use of pacifier, and time lapse before the first breastfeeding (9-13). The use of complementary feeds during hospital stay, maternal and paternal smoking, maternal obesity, and an early return to work shorten the duration of breastfeeding $(14,15)$.

In Zhejiang province of China, the rural areas have not progressed as rapidly as the cities and urban areas while people from the rural west and nearby provinces continue to migrate to the major cities in search of more lucrative employment. In 2006, the population in Zhejiang was 49 million. A crosssectional survey undertaken in five cities of Zhejiang in 1997 found that the rate of exclusive breastfeeding before discharge was $74.4 \%$ but dropped to $43.7 \%$ by 10 weeks (16). This rate was lower than the target of the World Health Organization (WHO) for initiation and exclusive breastfeeding of six months. The purpose of this study was to document the breastfeeding rates and to identify the factors determining the duration of breastfeeding and the earlier introduction of infant formula in Zhejiang province. The findings are important for avoiding another melamine disaster in the future.

\section{MATERIALS AND METHODS}

\section{Study sample and site}

A prospective cohort study of breastfeeding was undertaken in Zhejiang province from October 2004 to December 2005. Participants were interviewed before discharge from hospital and at one, three, and six months postpartum. Mothers were recruited from Hangzhou (capital city of Zhejiang), a suburban area and a mountainous rural area, $300 \mathrm{~km}$ to the southwest. Of 1,551 mothers invited to participate, 1,520 (98\%) agreed and consented to the study. Three hospitals were selected to be representative of the healthcare facilities of city, suburban and rural areas. Random selection of mothers was adopted in the larger facilities where a number of deliveries occurred on a particular day. The inclusion criteria for the study were: delivery of a live child; both mother and neonate did not have any serious illness; and the mother was a resident within the service area of the hospital.

\section{Collection of data}

The questionnaire solicited information on infantfeeding methods and variables likely to affect the duration of breastfeeding. It was based on validated and reliable instruments that have been extensively used in cohort studies on breastfeeding in China, Australia, Viet Nam, and Kenya (17-21). The questionnaire was translated into Mandarin and backtranslated by professionals. Its appropriateness and cultural relevance were confirmed via focus groups. All interviews were conducted by staff familiar with the local Zhejiang dialect.

\section{Definitions}

The definitions used in a previous study (11) were adopted as follows:

- Any breastfeeding: The child has received breastmilk (direct from the breast or expressed) with or without other drinks, formula, or infant food.

- Exclusive breastfeeding: Breastfeeding while giving no other food or liquid, not even water, with the exception of drops of syrups consisting of vitamins, mineral supplements, or medicine.

- Full breastfeeding: Almost exclusive breastfeeding with only small amounts of other fluids.

\section{Analysis of data}

Data were entered and analyzed using the SPSS software (version 14.0) (SPSS Inc., Chicago, IL, USA). Survival analysis was performed on those women who still breastfed at the time of discharge. The duration of breastfeeding was estimated by the Kaplan-Meier method and compared between groups using the log-rank test. Cox proportional hazards regression was then applied to determine the factors affecting the duration of 'any' and 'exclusive' breastfeeding, with significant variables selected based on the backward elimination procedure. Logistic regression analysis was conducted to identify the factors associated with the earlier introduction of infant formula.

\section{Ethics}

Approval of ethics was obtained from the Human Research Ethics Committee of Curtin University and the participating hospitals in China. All participants were assured of confidentiality and their right to withdraw at any time. Data were subsequently de-identified to ensure privacy of the information collected.

\section{RESULTS}

Demographic characteristics of the sample, together with the percentage of mothers still breastfeeding at six months, are shown in Table 1 . The use of prelacteal formula feeds was common, with 


\begin{tabular}{|c|c|c|c|c|}
\hline Factor & No. & $\%$ & $95 \%$ CI & $\mathrm{p}$ value \\
\hline Maternal education (years) & & & & $<0.001$ \\
\hline$\leq 9$ & 539 & 84 & $80.1-87.9$ & \\
\hline $10-12$ & 370 & 71 & $65.1-76.9$ & \\
\hline$\geq 13$ & 595 & 67 & $63.1-70.9$ & \\
\hline Maternal profession & & & & 0.002 \\
\hline Labour & 490 & 81 & $77.1-84.9$ & \\
\hline Office work & 758 & 69 & $65.1-72.9$ & \\
\hline Not working & 222 & 76 & $70.1-81.9$ & \\
\hline Maternal age (years) & & & & 0.231 \\
\hline$\leq 24$ & 355 & 77 & $71.1-82.9$ & \\
\hline $25-29$ & 800 & 72 & 68.1-75.9 & \\
\hline$\geq 30$ & 335 & 78 & $72.1-83.9$ & \\
\hline Maternal salary (Yuan) & & & & $<0.001$ \\
\hline$\leq 3,000$ & 609 & 83 & 79.1-86.9 & \\
\hline $3,000-5,000$ & 452 & 73 & $67.1-78.9$ & \\
\hline$\geq 5,001$ & 406 & 61 & $55.1-66.9$ & \\
\hline Gestation (weeks) & & & & $<0.001$ \\
\hline$<37$ & 48 & 47 & 29.4-64.6 & \\
\hline$\geq 37$ & 1,438 & 76 & $74.0-78.0$ & \\
\hline Birthweight (g) & & & & 0.443 \\
\hline$\leq 2,499$ & 27 & 73 & $55.4-90.6$ & \\
\hline $2,500-3,999$ & 1,377 & 75 & $73.0-77.0$ & \\
\hline$\geq 4,000$ & 96 & 74 & $64.2-83.8$ & \\
\hline Parity & & & & 0.018 \\
\hline Primiparous & 1,341 & 74 & $72.0-76.0$ & \\
\hline Multiparous & 162 & 85 & $79.1-90.9$ & \\
\hline Delivery method & & & & 0.268 \\
\hline Vaginal & 492 & 76 & $72.1-79.9$ & \\
\hline Caesarean & 1,015 & 74 & $70.1-77.9$ & \\
\hline Breastfeeding decision made & & & & $<0.001$ \\
\hline Before pregnancy & 1,087 & 78 & 74.1-81.9 & \\
\hline During pregnancy & 260 & 70 & $64.1-75.9$ & \\
\hline After birth & 152 & 65 & $57.2-72.8$ & \\
\hline Maternal grandmother breastfed & & & & 0.312 \\
\hline Yes & 1,398 & 75 & 73.0-77.0 & \\
\hline No & 80 & 63 & $49.3-76.7$ & \\
\hline Infant admitted to special-care nursery & & & & $<0.001$ \\
\hline Yes & 149 & 59 & $49.2-68.8$ & \\
\hline No & 1,324 & 76 & $74.0-78.0$ & \\
\hline Suck time (minutes) & & & & 0.027 \\
\hline$\leq 30$ & 480 & 79 & $75.1-82.9$ & \\
\hline$>30$ & 960 & 75 & 71.1-78.9 & \\
\hline Mother attended antenatal classes & & & & 0.937 \\
\hline Yes & 949 & 73 & $69.1-76.9$ & \\
\hline No & 549 & 77 & $73.1-80.9$ & \\
\hline First feed & & & & $<0.001$ \\
\hline Breastmilk & 927 & 77 & 73.1-80.9 & \\
\hline \multirow[t]{2}{*}{ Other } & 551 & 71 & $67.1-74.9$ & \\
\hline & & & & Contd. \\
\hline
\end{tabular}




\begin{tabular}{|lcccc|}
\hline Table 1.- Contd. & & & & \\
\hline Factor & No. & $\%$ & $95 \%$ CI & p value \\
\hline Baby's gender & & & & 0.800 \\
$\quad$ Male & 769 & 74 & $70.1-77.9$ & \\
$\quad$ Female & 728 & 75 & $71.1-78.9$ & \\
Location & & & & $<0.001$ \\
$\quad$ City & 638 & 63 & $57.1-68.9$ & \\
$\quad$ Suburban & 346 & 77 & $71.1-82.9$ & \\
$\quad$ Rural & 524 & 84 & $80.1-87.9$ & \\
Back to work & & & & $<0.001$ \\
$\quad$ Before 6 months & 497 & 64 & $60.1-67.9$ & \\
$\quad$ After 6 months & 771 & 81 & $77.1-84.9$ & \\
Consume water & & & & \\
$\quad$ Within 1 month & 538 & 65 & $59.1-70.9$ & \\
$\quad$ After 1 month & 947 & 80 & $78.0-82.0$ & \\
Introduction of complementary food & & & & 0.001 \\
$\quad$ Within 3 months & 439 & 69 & $65.1-72.9$ & \\
$\quad$ After 3 months & 853 & 77 & $73.1-80.9$ & \\
\hline CI=Confidence interval & & & & \\
\hline
\end{tabular}

the prevalence of $62.0 \%, 36.6 \%$, and $39 \%$ in the city, suburban and rural areas respectively (22). The any breastfeeding rate at discharge from hospital was $96.9 \%$ overall but dropped to $74 \%$ after six months-similar in all the three locations.

Table 2 shows the details of exclusive breastfeeding in relation to the demographic and other factors. The rates of exclusive breastfeeding on discharge$38 \%$ in city, $63.4 \%$ in suburban, and $61 \%$ in rural areas-differed significantly among the three locations. The durations of exclusive, full and any breastfeeding in Zhejiang province are presented in Figure 1 . The mean ages for the introduction of infant formula were 3.3 (city), 4.7 (suburban), and 4.4 (rural) months (Table 3).
Table 4 presents the results of the Cox regression analysis for the duration of any breastfeeding. The risk of cessation of any breastfeeding was inversely related to age. The timing of the breastfeeding decision was also a significant factor. The adjusted risk of discontinuing any breastfeeding before six months was higher among mothers who made the breastfeeding decision after pregnancy [hazard ratio $(\mathrm{HR})=1.64,95 \%$ confidence interval (CI) 1.10 2.43] than those who made their breastfeeding decision before becoming pregnant. Other significant factors were being admitted to special-care nursery, earlier return of the mother to work (Fig. 2), being given water to drink before one month, early introduction of complementary foods, and the family's place of residence (Fig. 3).

\section{Fig. 1. Duration of breastfeeding (any, full, and exclusive) in Zhejiang province, China, 2004-2005}

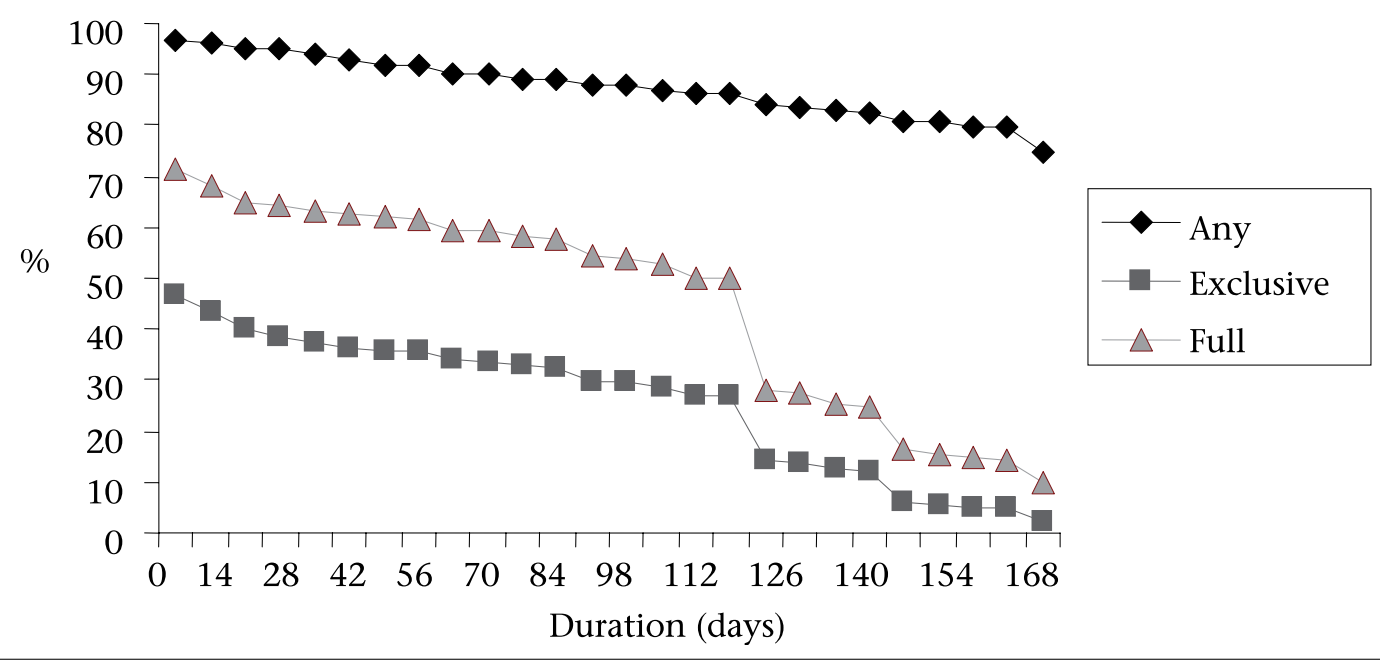




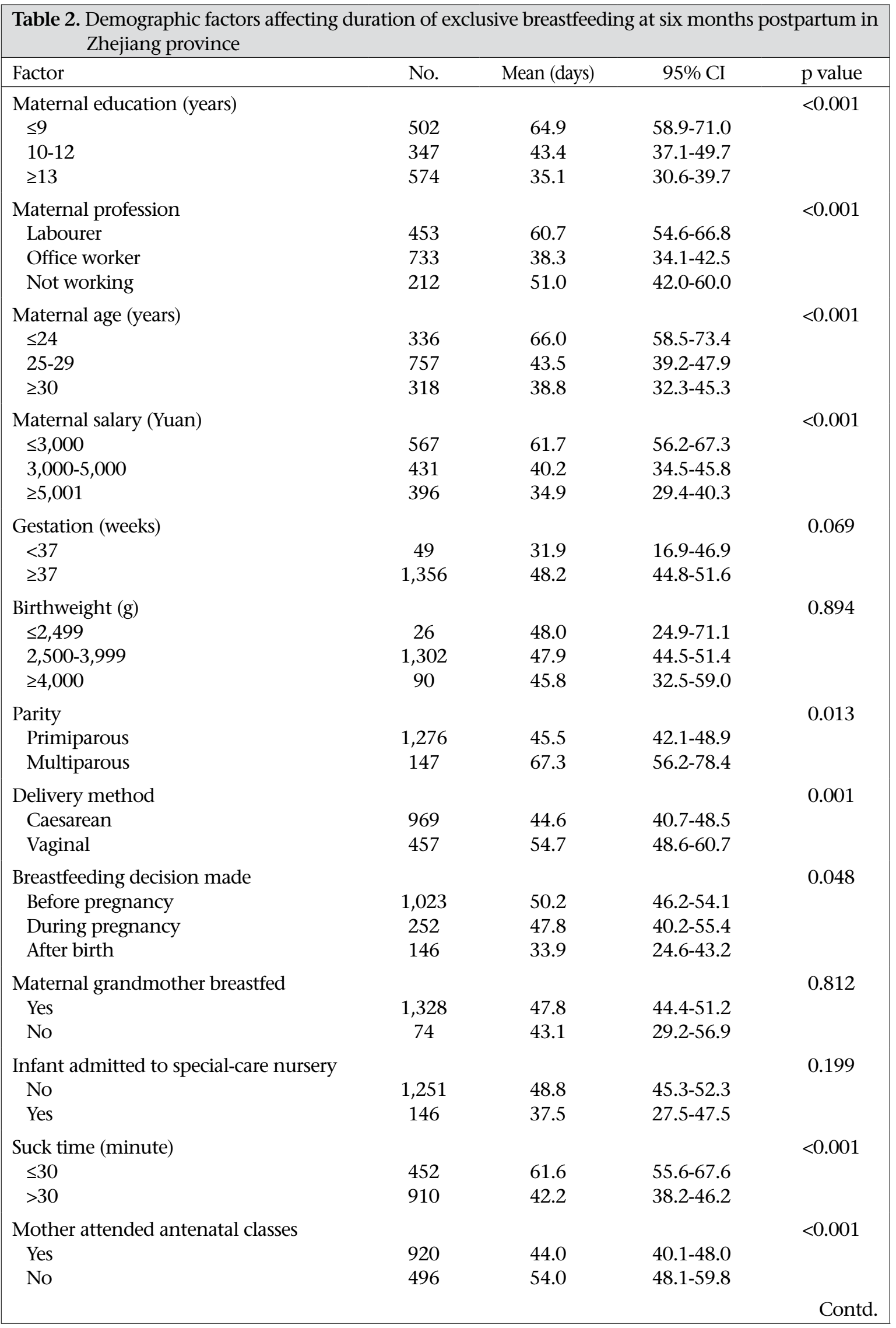




\begin{tabular}{|c|c|c|c|c|}
\hline Factor & No. & Mean (days) & $95 \% \mathrm{CI}$ & $\mathrm{p}$ value \\
\hline First feed & & & & 0.041 \\
\hline Breastmilk & 890 & 51.4 & $47.2-55.5$ & \\
\hline Other & 509 & 40.4 & $35.0-45.7$ & \\
\hline Baby's gender & & & & 0.063 \\
\hline Male & 719 & 45.1 & $40.6-49.7$ & \\
\hline Female & 699 & 50.8 & $46.0-55.5$ & \\
\hline Location & & & & $<0.001$ \\
\hline City & 634 & 30.0 & $26.0-34.0$ & \\
\hline Suburban & 344 & 64.2 & 57.3-71.1 & \\
\hline Rural & 448 & 59.2 & $52.9-65.6$ & \\
\hline \multicolumn{4}{|l|}{ Back to work } & \multirow{3}{*}{$<0.001$} \\
\hline Before 6 months & 473 & 39.4 & $34.3-44.4$ & \\
\hline After 6 months & 714 & 60.4 & $55.5-65.4$ & \\
\hline $\mathrm{CI}=$ Confidence int & & & & \\
\hline
\end{tabular}

Fig. 2. Duration of any breastfeeding up to six months postpartum by status of returning to work

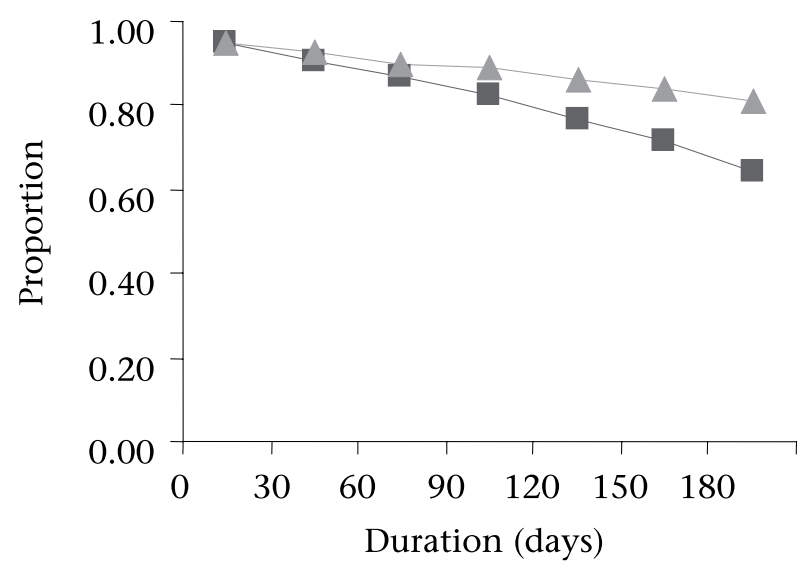

- Back to work $\leq 6$ months Back to work $>6$ months

Table 3. Introduction of infant formula in Zhejiang province

Age when infant formula introduced

\begin{tabular}{|c|c|c|c|c|c|c|c|c|c|c|}
\hline \multirow[t]{2}{*}{ Location* } & \multicolumn{2}{|c|}{ At discharge } & \multicolumn{2}{|c|}{ One month } & \multicolumn{2}{|c|}{ Three months } & \multicolumn{2}{|c|}{ Six months } & \multicolumn{2}{|c|}{ More than six months } \\
\hline & No. & $\%$ & No. & $\%$ & No. & $\%$ & No. & $\%$ & No. & $\%$ \\
\hline City & 380 & 67.7 & 70 & 12.5 & 47 & 8.4 & 62 & 11.1 & 2 & 0.4 \\
\hline Suburban & 123 & 36.9 & 42 & 12.6 & 20 & 6.0 & 145 & 43.5 & 3 & 0.9 \\
\hline Rural & 202 & 39.8 & 62 & 12.2 & 41 & 8.1 & 168 & 33.3 & 34 & 6.7 \\
\hline
\end{tabular}

Table 5 presents the results of Cox regression analysis for exclusive breastfeeding. The two significant factors were: mothers who returned to work within six months of delivery and place of residence. Factors associated with the introduction of formula before three months are shown in Table 6. Mothers who made their breastfeeding decision during pregnancy and after the baby's birth were more likely to feed their babies using formula before three months when compared with others who decided before becoming pregnant. Infants whose first feed was not breastmilk were also more likely to be subsequently fed with formula. However, rural mothers were less likely to introduce formula to their babies before three months.

\section{DISCUSSION}

Following the melamine crisis, the Zhejiang publichealth authorities attempted to contact all infants aged 0-3 years-in total, 1.54 million infants. During 2007, of 581,068 reported livebirths, 197,382 (34\%) were from parents who migrated from an- 


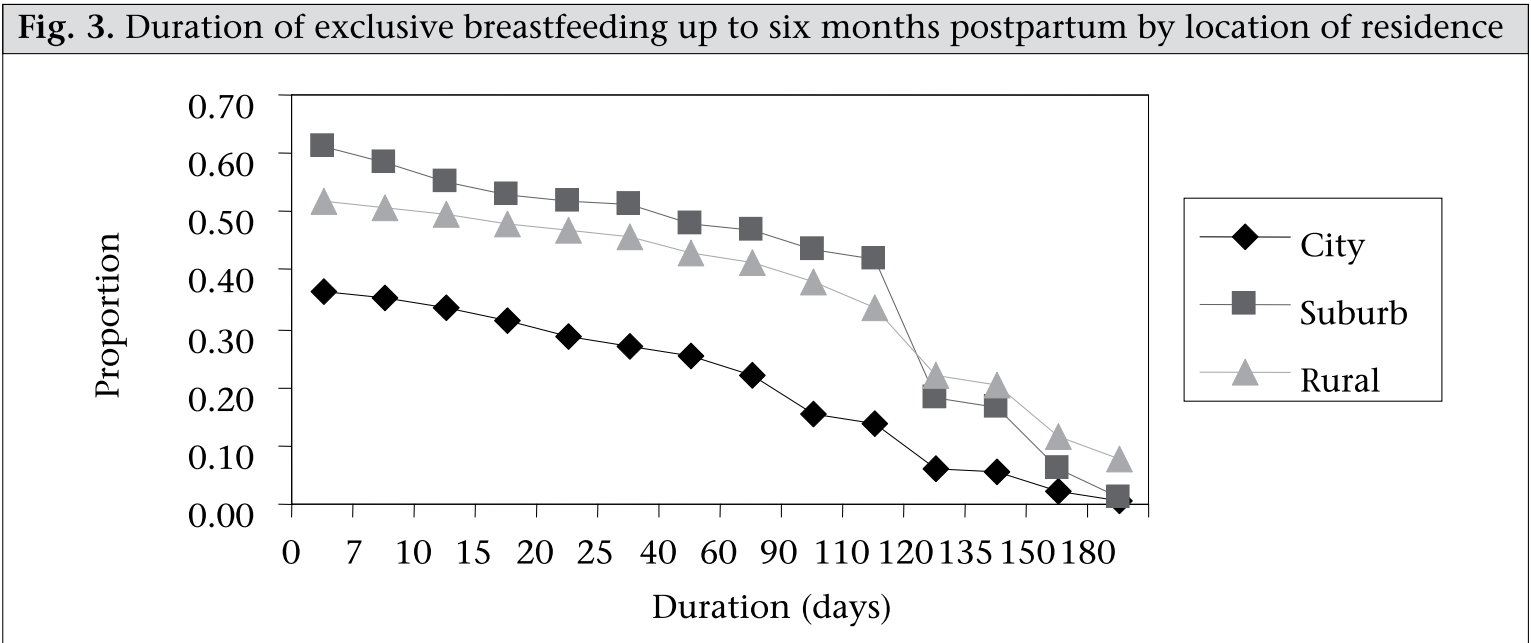

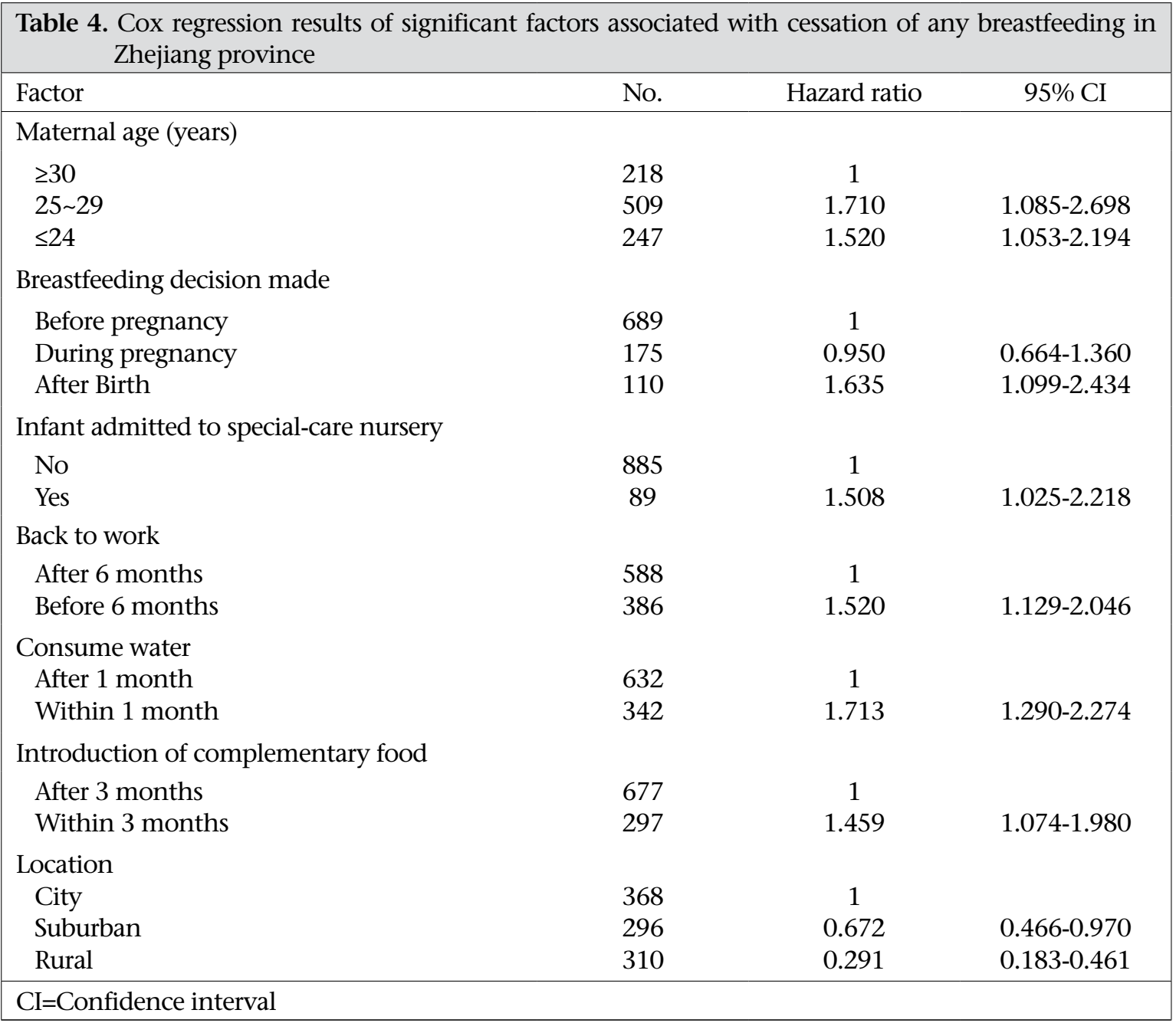

other province (23). The contaminated formulae were inexpensive domestic brands mainly consumed by migrants. For example, 1,229 (73\%) of 1,673 infants in a Hangzhou migrant community had been fed with contaminated infant formula at an early age.
The common factors associated with the durations of both exclusive and any breastfeeding were the location of residence of mothers and their early return to work. The infant-feeding practices were different in the rural, suburban and city areas of Zhejiang province (24). The importance of exclusive 


\begin{tabular}{|lrcc|}
\hline $\begin{array}{r}\text { Table 5. Cox regression results of significant fac- } \\
\text { tors associated with cessation of exclu- } \\
\text { sive breastfeeding in Zhejiang province }\end{array}$ \\
\hline Factor & No. & $\begin{array}{c}\text { Hazard } \\
\text { ratio }\end{array}$ & 95\% CI \\
\hline Back to work & & & \\
After 6 months & 337 & 1 & \\
Before 6 months & 174 & 1.471 & $1.204-1.796$ \\
Location & & & \\
$\quad$ City & 171 & 1 & \\
$\quad \begin{array}{l}\text { Suburban } \\
\text { Rural }\end{array}$ & 189 & 0.739 & $0.595-0.918$ \\
\hline CI=Confidence interval & 151 & 0.590 & $0.462-0.754$ \\
\hline
\end{tabular}

The timing of the breastfeeding decision was known to relate to breastfeeding outcomes in various cultures $(10,31)$. This was the case in the present study, and it also influenced the early introduction of infant formula. Health professionals should encourage prospective parents to consider breastfeeding at the earliest opportunity and continue to emphasize the advantages of breastfeeding during subsequent antenatal visits.

Most infants (city-99.8\%, suburban-99.5\%, and rural-92.8\%) had consumed or were consuming some infant formula by six months. Education and health-promotion programmes taking the above factors into account to improve the duration of

\begin{tabular}{|c|c|c|c|}
\hline Factor & No. & Odds ratio & $95 \% \mathrm{CI}$ \\
\hline \multicolumn{4}{|c|}{ Breastfeeding decision made } \\
\hline Before pregnancy & 764 & 1 & \\
\hline During pregnancy & 195 & 1.865 & $1.150-3.023$ \\
\hline After birth & 121 & 3.093 & $1.814-5.275$ \\
\hline \multicolumn{4}{|l|}{ First feed } \\
\hline Breastmilk & 643 & 1 & \\
\hline Other & 437 & 2.177 & $1.429-3.317$ \\
\hline \multicolumn{4}{|l|}{ Location } \\
\hline City & 395 & 1 & \\
\hline Suburban & 321 & 0.833 & $0.510-1.323$ \\
\hline Rural & 364 & 0.417 & $0.248-0.701$ \\
\hline
\end{tabular}

breastfeeding up to six months of age (and breastfeeding beyond that time) is recognized $(25,26)$. To support breastfeeding, the Zhejiang Provincial Council has passed regulations to extend maternity leave from six weeks to three months, and employers are requested to ensure that mothers have sufficient time for breastfeeding their infants. Like other countries (27), Chinese mothers should be allowed sufficient time away from work to make feeding arrangements, although employment has less effect in situations where the infant is able to accompany the mother (20).

Another factor that adversely affected the duration of any breastfeeding was the feeding of liquids or food. With the early introduction of complementary foods, the breast receives less stimulation from suckling, resulting in the decrease in the production of milk (28-30). Mothers should be encouraged to delay the introduction of complementary foods until at least six months of age. The influence of complementary foods was consistent with results of previous studies in China $(12,21)$. breastfeeding would reduce the risk associated with the consumption of infant formula. The recent contamination episode in China has resulted in the withdrawal of many local infant formula brands from the market. Mothers have few options to feed their infants. They can attempt to relactate, feed international infant formula brands at 3-4 times increased costs. In some instances, they may seek cheaper substitutes, such as cow's milk or even less healthy options (32).

Several limitations must be considered when interpreting the results of the present study. The study sites were restricted to three locations in Zhejiang province based on the financial and logistical support available for this project. While the study locations were selected to be representative of Zhejiang province, further replications at other sites would strengthen the generalizability of the findings. This study was terminated after six months from hospital discharge. A longer follow-up period is recommended in future studies.

In conclusion, this is the first longitudinal cohort 
study reporting the infant-feeding practices in Zhejiang province of China. The overall rate of any breastfeeding was high but dropped to $74 \%$ after six months. Fewer than $5 \%$ of the infants reached the WHO and Chinese targets of exclusive breastfeeding until six months of age. The use-rate of infant formula was extremely high (98\%), exposing infants to the risk of diseases from contaminated formula. Strategies must be developed to reduce the early introduction of infant formula and to improve the duration of breastfeeding to avoid another melamine disaster in the future.

\section{ACKNOWLEDGEMENTS}

The authors gratefully acknowledge the willing assistance given by the mothers, the hospital staff, nurses, and health workers participating in this study.

\section{REFERENCES}

1. UBIC Consulting. Ingredients for infant formula market. 2009. (http://www.ubic-consulting.com/ food/ingredient/chemical-industries/ipsum-dolor-officia.html, accessed on 16 February 2010).

2. World Health Organization. Melamine-contamination event, China, September 2008 (a WHO statement). Geneva: World Health Organization, 2008. 1 p.

3. International Agency for Research on Cancer. Melamine case no. 108-78-1. International Agency for Research on Cancer-summaries \& evaluations. Lyon: International Agency for Research on Cancer, 1986;39:333-43.

4. Jones G, Steketee R, Black R, Bhutta Z, Morris S; Bellagio Child Survival Study Group. How many child deaths can we prevent this year? Lancet 2003;362:65-71.

5. Binns C, Davidson G. Infant feeding guidelines for health workers. Dietary guidelines for children in Australia. Canberra: National Health and Medical Research Council, 2003. 257 p.

6. World Health Organization. Global strategy for infant and young child feeding Geneva: World Health Organization, 2003. 1 p.

7. American Academy of Pediatrics. Breastfeeding and the use of human milk. Pediatrics 2005;115:496-505.

8. He J, Wang F. Baby friendly action in China. Beijing: Department of Maternal and Child Health, Ministry of Public Health, People's Republic of China, 1994:2-3.

9. Binns C, Scott J. Using pacifiers: what are breastfeeding mothers doing? Breastfeeding Rev 2002;10:21-6.

10. Duong DV, Lee AH, Binns CW. Determinants of breastfeeding within the first 6 months post-partum in rural Vietnam. J Paediatr Child Health 2005;41:338-43.
11. Xu F, Binns C, Wu J, Yihan R, Zhao Y, Lee A. Infant feeding practices in Xinjiang Uygur Autonomous Region, People's Republic of China. Public Health Nutr 2007;10:198-202.

12. Xu F, Binns C, Zheng S, Wang Y, Zhao Y, Lee A. Determinants of exclusive breastfeeding duration in Xinjiang, PR China. Asia Pac J Clin Nutr 2007;16:316-21.

13. Donath SM, Amir LH. Does maternal obesity adversely affect breastfeeding initiation and duration? J Paediatr Child Health 2000;36:482-6.

14. Novotny R, Hla MM, Kieffer EC, Park CB, Mor J, Thiele M. Breastfeeding duration in a multiethnic population in Hawaii. Birth 2000;27:91-6.

15. Xu F, Binns C, Zhang H, Yang G, Zhao Y. Parental smoking and breastfeeding in Xinjiang, PR China: a cohort study. J Hum Lact 2010 (in press).

16. Qiu $\mathrm{L}$, Wang $\mathrm{Q}, \mathrm{Li}$ R. The survey of breastfeeding in city, Zhejiang province. Zhejiang Preven Med 1998;(6):347-9.

17. Scott JA, Landers MC, Hughes RM, Binns CW. Factors associated with breastfeeding at discharge and duration of breastfeeding. J Paediatr Child Health 2001;37:254-61.

18. Scott JA, Aitkin I, Binns CW, Aroni RA. Factors associated with the duration of breastfeeding amongst women in Perth, Australia. Acta Paediatr 1999;88:416-21.

19. Duong DV, Binns CW, Lee AH. Breast-feeding initiation and exclusive breast-feeding in rural Vietnam. Public Health Nutr 2004;7:795-9.

20. Lakati A, Binns C, Stevenson M. The effect of work status on exclusive breastfeeding in Nairobi. Asia Pac J Public Health 2002;14:85-90.

21. Xu F, Binns C, Yu P, Bai Y. Determinants of breastfeeding initiation in Xinjiang, PR China, 2003-2004. Acta Paediatr 2007;96:257-60.

22. Qiu L, Xie X, Lee A, Binns CW. Infants' first feeds in Hangzhou, PR China. Asia Pac JClin Nutr 2007;16(Suppl 1):458-61.

23. Zhejiang Province Health Bureau. Zhejiang maternal and child health statistic annual report 2007. Zhejiang: Zhejiang Province Health Bureau, 2007:4-5.

24. Qiu L, Zhao Y, Binns CW, Lee AH, Xie X. A cohort study of infant feeding practices in city, suburban and rural areas in Zhejiang province, PR China. Int Breastfeed J 2008;3:4.

25. Ip S, Chung M, Raman G, Chew P, Magula N, DeVine $\mathrm{D}$ et al. Breastfeeding and maternal and infant health outcomes in developed countries. Evid Rep Technol Assess (Full Rep). 2007(153):1-186.

26. World Health Organisation. The optimal duration of exclusive breastfeeding. Geneva: World Health Organization, 2001. 2 p. (WHO/NHD/01.09, WHO/FCH/ 
$\mathrm{CAH} / 01.24)$.

27. Cooklin AR, Donath SM, Amir LH. Maternal employment and breastfeeding: results from the longitudinal study of Australian children. Acta Paediatr 2008;97:620-3.

28. Cohen RJ, Brown KH, Canahuati J, Rivera LL, Dewey KG. Effects of age of introduction of complementary foods on infants breastmilk intake, total energy intake, and growth: a randomized intervention study in Honduras. Lancet 1994;344:288-93.

29. World Health Organization. Complementary feeding of young children in developing countries. Geneva: World Health Organization, 1998. 39 p. (WHO/
NUT/98.1).

30. Binns CW, Davidson GP. NHMRC infant feeding guidelines. Dietary guidelines for children. Canberra: National Health and Medical Research Council, 2003. $344 \mathrm{p}$.

31. Scott JA, Binns CW, Graham KI, Oddy WH. Temporal changes in the determinants of breastfeeding initiation. Birth 2006;33:37-45.

32. Barennes H, Andriatahina T, Latthaphasavang V, Anderson M, Srour LM. Misperceptions and misuse of Bear Brand coffee creamer as infant food: national cross sectional survey of consumers and paediatricians in Laos. BMJ 2008;337:a1379. 